\title{
Removal of well-fixed, cementless, acetabular components in revision hip arthroplasty
}

\author{
P. A. Mitchell, B. A. Masri, D. S. Garbuz, N. V. Greidanus, \\ D. Wilson, C. P. Duncan \\ From the University of British Columbia, Vancouver, Canada
}

$\mathbf{R}$ emoval of well-fixed, cementless, acetabular components during revision arthroplasty remains a challenging problem. Further damage to host bone may limit options for reconstruction and compromise the long-term result of the revision operation. We report the results of 31 hips with well-fixed, cementless sockets which were removed using a new cup extraction system. In all hips the socket was removed without difficulty and with minimal further bone loss.

J Bone Joint Surg [Br] 2003;85-B:949-52.

Received 28 May 2002; Accepted 23 April 2003

In revision total hip arthroplasty (THA) well-fixed, cementless implants have to be removed in cases of malposition, with or without instability of infection and, in some cases, excessive polyethylene wear. ${ }^{1}$ The aim is to remove the components while causing minimal damage to host bone. Secure, cementless components present a particular challenge. ${ }^{2,3}$ In this situation, there is potential for further damage to the pelvis, thus compromising the options for further reconstruction.

The usual method for removing cementless, acetabular components involves identifying the bone-implant interface and developing this plane with cutting instruments, such as curved osteotomes. This process can further damage the existing bone stock because of the uncertainty as to when the interface has been sufficiently weakened to extract the acetabular shell without removing host bone.

P. A. Mitchell, FRCS (Trauma \& Orth), Clinical and Research Fellow B. A. Masri, MD, FRCS C, Associate Professor and Head

D. S. Garbuz, MD, MHSc, FRCS C, Assistant Professor

N. V. Greidanus, MD, MPH, FRCS C, Assistant Professor

D. Wilson, FRCS (Trauma \& Orth), Clinical and Research Fellow

C. P. Duncan, MD, FRCS C, Professor and Chairman

Division of Lower Limb Reconstruction and Oncology, Department of Orthopaedics, University of British Columbia, Third Floor, 910 West Tenth Avenue, Vancouver V5Z 4E1, British Columbia, Canada.

Correspondence should be sent to Dr B. A. Masri.

(C)2003 British Editorial Society of Bone and Joint Surgery doi:10.1302/0301-620X.85B7.13593\$2.00
We present our experience of 31 patients from whom secure, cementless, acetabular components were removed using a new technique. The main premise of this technique is the ability to debond the component from the surrounding bone.

\section{Patients and Methods}

A series of 31 consecutive patients who underwent removal of a secure, acetabular component at the time of revision arthroplasty were included for review. Standard pre-operative radiographs were taken, including a plain anteroposterior view of the pelvis, and iliac and obturator views of the acetabulum. Acetabular bone deficiencies were classified pre-operatively from the radiographs and after removal of the implant, according to the system of the American Academy of Orthopaedic Surgeons (AAOS). ${ }^{4}$ Pre-operative radiographs were reviewed independently to assess any defects and to determine the approximate size of the replacement component needed. In hips where the indication for revision was infection, a two-stage technique was employed. We used templating in these hips to determine the size of the defect after removal of the implant. During the operative procedure, the size of the component which was removed and the diameter of the final reamer used prior to implantation were recorded. The comparison between these two measurements allowed us to assess how much host bone was removed during removal of the implant. The size of the final reamer was a more accurate indicator of host bone loss than the size of the component implanted, as we routinely under-ream the socket by at least $2 \mathrm{~mm}$ when undertaking cementless, acetabular revision.

Operative technique. For removal of the well-fixed cementless, acetabular components we used the Explant Acetabular Cup Removal System (Zimmer, Warsaw, Indiana). This system consists of a rotating handle, connected to an acetabular liner centring device, which drives a curved cutting blade around the outside of the acetabular shell at the boneimplant interface (Fig. 1). Two blades are used sequentially. The first, a short blade, penetrates the dense peripheral bone thus creating a channel and the second, a thin, full-radius blade, frees the dome of the cup from the iliac bone (Fig. 2). Both blades are tapered at the cutting edges and are approximately $2 \mathrm{~mm}$ thick and because the second blade is of full 


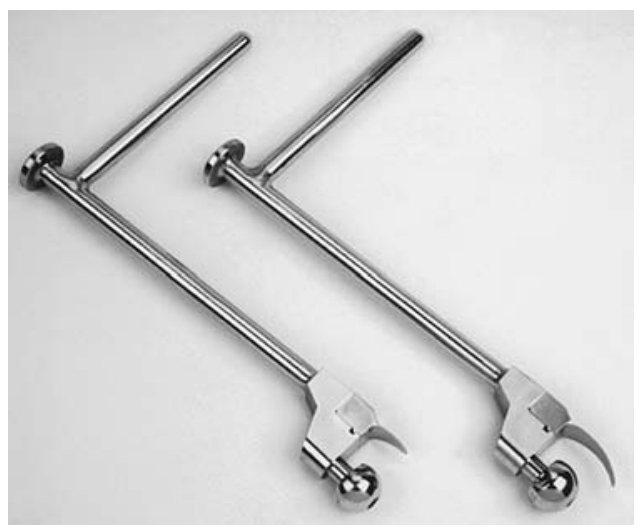

Fig. 1

The Explant System used to remove well-fixed, acetabular, cementless components.

radius, the implant can simply be lifted out of its bed between the blade and the handle.

There are three absolute requirements for successful use of this system. First, the external diameter of the acetabular shell must be known, as the blades are size specific, closely matching the external diameter of the cup. If the blades are oversized more bone may be removed than necessary. Secondly, a liner, of known diameter, must be present to position the centring head of the Explant tool in the cup. If the liner is eccentrically worn and thus unsuitable, it must be removed and a trial liner inserted of the same external diameter. The centring heads of the system are available in diameters of 22, 26, 28 and $32 \mathrm{~mm}$. With experience, by rotating the worn liner so that its thickest portion is adjacent to the cutting blade, it is possible to control the position of the centring head despite polyethylene wear. Thirdly, the external geometry of the shell must be known. The system works best when removing hemispherical shells, although non-hemispherical, dual-radius and spiked implants can be removed in the same way with adjustment of the technique.

It is not essential to know the identity of the manufacturer of the implant, as long as the above details are known; nevertheless, we routinely request the implant labels from the previous operation.

\section{Results}

We reviewed the results of extraction of the cup using the Explant System in our first 31 consecutive patients as this would include the steepest part of the learning curve. No patient was excluded. There were 15 men and 16 women, with a mean age of 65.2 years (49 to 86). In all patients the indication for arthroplasty was osteoarthritis. The indications for acetabular revision were infection, polyethylene wear, locking mechanism failure and malposition. The mean interval between initial and revision surgery was 6.7 years (one to 11). The patient demographics are summarised in Table I. All cups were judged to be well-fixed according to

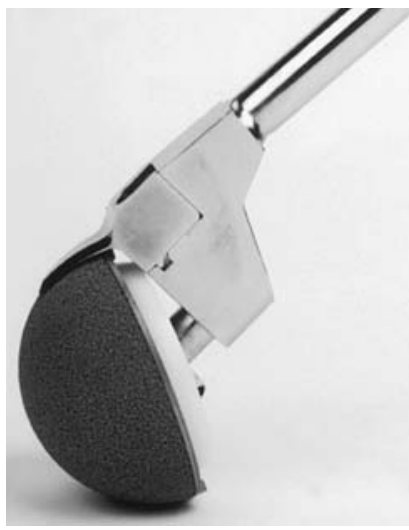

Fig. 2a

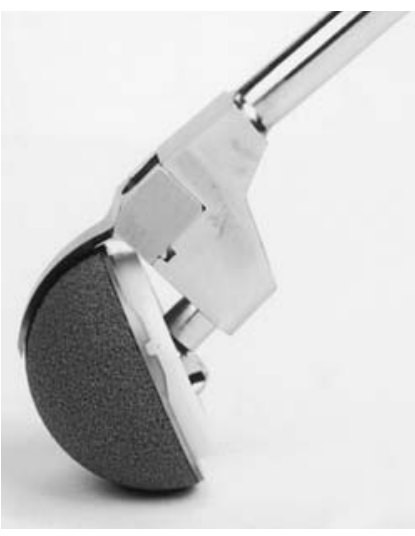

Fig. 2b
The two blades used by the Explant System. a) The short blade and b) the full-radius blade.

Table I. Details of the 31 patients who underwent revision arthroplasty

\begin{tabular}{|c|c|c|c|c|c|}
\hline Case & $\begin{array}{l}\text { Age } \\
\text { (yrs) }\end{array}$ & Gender & $\begin{array}{l}\text { Duration of } \\
\text { implantation } \\
\text { (yrs) }\end{array}$ & $\begin{array}{l}\text { Indication for } \\
\text { revision }\end{array}$ & $\begin{array}{l}\text { Acetabular } \\
\text { defect }\end{array}$ \\
\hline 1 & 59 & M & 4 & Lock failure & Cavitary \\
\hline 2 & 71 & $\mathrm{~F}$ & 6 & Infection & Cavitary \\
\hline 3 & 77 & M & 4 & Infection & Nil \\
\hline 4 & 64 & $\mathrm{~F}$ & 1 & Infection & Cavitary \\
\hline 5 & 66 & M & 11 & Malposition & Nil \\
\hline 6 & 77 & $\mathrm{~F}$ & 4 & Malposition & Nil \\
\hline 7 & 72 & M & 7 & Lock failure & Cavitary \\
\hline 8 & 81 & M & 5 & Malposition & Cavitary \\
\hline 9 & 69 & M & 1 & Infection & Nil \\
\hline 10 & 53 & $\mathrm{~F}$ & 10 & Polyethylene wear & Nil \\
\hline 11 & 49 & M & 11 & Polyethylene wear & Cavitary \\
\hline 12 & 67 & $\mathrm{~F}$ & 10 & Polyethylene wear & Cavitary \\
\hline 13 & 51 & $\mathrm{~F}$ & 2 & Malposition & Nil \\
\hline 14 & 77 & M & 5 & Malposition & Nil \\
\hline 15 & 71 & $\mathrm{~F}$ & 10 & Malposition & Nil \\
\hline 16 & 58 & M & 4 & Infection & Segmental \\
\hline 17 & 53 & M & 5 & Malposition & Nil \\
\hline 18 & 65 & $\mathrm{~F}$ & 5 & Malposition & Nil \\
\hline 19 & 71 & M & 5 & Infection & Nil \\
\hline 20 & 64 & $\mathrm{~F}$ & 12 & Polyethylene wear & Cavitary \\
\hline 21 & 80 & M & 2 & Infection & Nil \\
\hline 22 & 62 & $\mathrm{~F}$ & 9 & Malposition & Nil \\
\hline 23 & 48 & M & 7 & Polyethylene wear & Cavitary \\
\hline 24 & 78 & $\mathrm{~F}$ & 7 & Polyethylene wear & Nil \\
\hline 25 & 86 & $\mathrm{~F}$ & 13 & Polyethylene wear & Cavitary \\
\hline 26 & 64 & M & 4 & Malposition & Cavitary \\
\hline 27 & 37 & M & 14 & Polyethylene wear & Cavitary \\
\hline 28 & 63 & $\mathrm{~F}$ & 8 & Polyethylene wear & Nil \\
\hline 29 & 38 & $\mathrm{~F}$ & 5 & Malposition & Nil \\
\hline 30 & 79 & $\mathrm{~F}$ & 9 & Malposition & Nil \\
\hline 31 & 72 & $\mathrm{~F}$ & 8 & Lock failure & Nil \\
\hline
\end{tabular}

the criteria of Udomkiat, Wan and Dorr, ${ }^{5}$ and all were found, at operation, to be well-fixed. Removal of the cup was effected rapidly and without complication in all hips. The time taken to remove the cup did not exceed five minutes in any hip. In one hip, where the cup was maloriented into retroversion and had a very tight rim fit rather than a polar fit, we removed a small sliver of bone measuring 


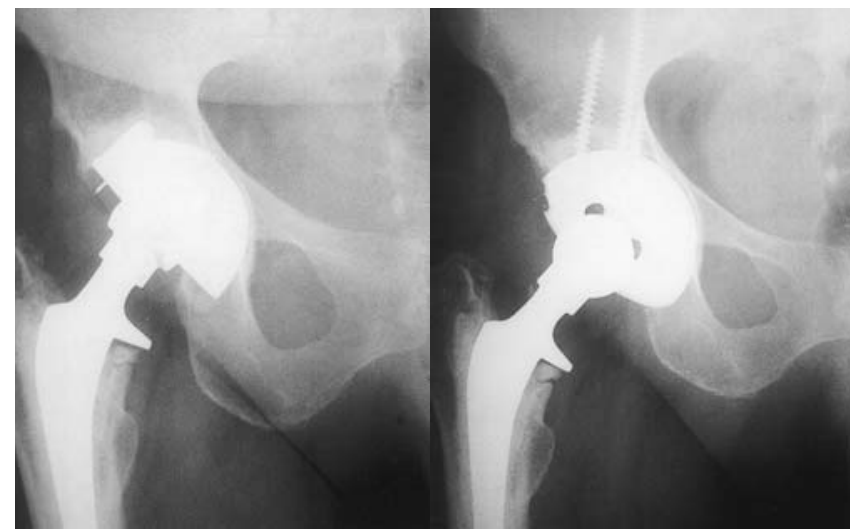

Fig. 3a

Fig. 3b

Radiographs of the pelvis with a) showing pre-operative evidence of a wellfixed, acetabular component, but eccentric polyethylene wear of the liner. The shell and liner were revised because of malposition. Note the position of the shell is medial to Kohler's line. b) The same patient, post-operatively. Minimal bone was lost during removal of the implant.

$4 \times 0.5 \mathrm{~cm}$ from the anterior rim of the acetabulum in the course of extraction. In three hips additional reaming to more than $4 \mathrm{~mm}$ was deliberately done in order to facilitate placement of a larger, constrained, tripolar socket. In all hips, including three in which the initial cup had been medialised to Kohler's line, the acetabular shell was removed without host bone (Figs 3 and 4).

The median difference between the size of component removed and the size of final reamer used was $4 \mathrm{~mm}$, indicating that no more host bone was removed than the thickness of the blades (Table II). In 13 hips the size of the final reamer was less than $4 \mathrm{~mm}$ greater than the size of the component removed. This may reflect elasticity in the acetabular bone as the tapered blades are moved through the boneimplant interface. In all patients the cup was a standard hemispherical implant, with supplementary screws and bone grafting of cavitary defects as required. The AAOS classification of acetabular deficiency did not change in any hip following removal of the implant. ${ }^{4}$

\section{Discussion}

Several techniques have been described for removal of wellfixed, cementless, acetabular components, which reflects the difficulty of the task. Mallory et $\mathrm{al}^{1}$ have described some aspects of removing a cup in the presence of osteolysis. Their chosen method of removal was to use curved osteotomes. Lachiewicz and Anspach ${ }^{6}$ and Anspach and Lachiewicz ${ }^{7}$ described a method using a pneumatic impact wrench, which could be used to remove cemented and cementless components. ${ }^{6,7}$ In their original series, however, one pelvic fracture and one technical failure were encountered. Daum and Calhoun ${ }^{8}$ described a method using an angled punch, which was placed against the acetabular component superiorly through a keyhole ( 3 to $4 \mathrm{~mm}$ ) made in

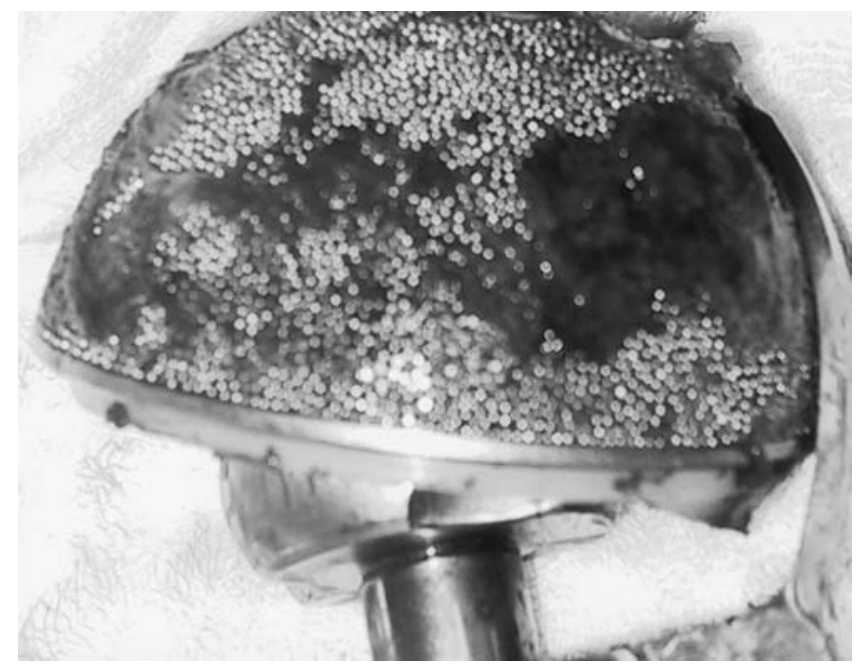

Fig. 4

Photograph showing the explanted cup devoid of bone.

Table II. The diameters of the implant removed, the final reamer used, the pre-operative template and the component implanted in the 31 patients who underwent revision arthroplasty

\begin{tabular}{|c|c|c|c|c|}
\hline Case & $\begin{array}{l}\text { Diameter } \\
\text { of implant } \\
\text { removed }(\mathrm{mm})\end{array}$ & $\begin{array}{l}\text { Diameter of } \\
\text { final reamer } \\
(\mathrm{mm})\end{array}$ & $\begin{array}{l}\text { Pre-operative } \\
\text { template } \\
(\mathrm{mm})\end{array}$ & $\begin{array}{l}\text { Diameter of } \\
\text { component } \\
\text { implanted }(\mathrm{mm})\end{array}$ \\
\hline 1 & 54 & 58 & 60 & 60 \\
\hline 2 & 56 & 60 & 62 & 62 \\
\hline 3 & 64 & 66 & 68 & 68 \\
\hline 4 & 62 & 66 & 68 & 68 \\
\hline 5 & 56 & 63 & 64 & 64 \\
\hline 6 & 56 & 58 & 60 & 60 \\
\hline 7 & 56 & 60 & 62 & 62 \\
\hline 8 & 48 & 58 & 58 & 58 \\
\hline 9 & 56 & 60 & 62 & 62 \\
\hline 10 & 56 & 60 & 62 & 62 \\
\hline 11 & 52 & 60 & 62 & 62 \\
\hline 12 & 48 & 50 & 52 & 52 \\
\hline 13 & 54 & 54 & 56 & 56 \\
\hline 14 & 56 & 59 & 60 & 60 \\
\hline 15 & 50 & 54 & 56 & 56 \\
\hline 16 & 54 & 58 & 60 & 60 \\
\hline 17 & 52 & 54 & 56 & 56 \\
\hline 18 & 62 & 64 & 66 & 66 \\
\hline 19 & 58 & 62 & 64 & 64 \\
\hline 20 & 46 & 54 & 56 & 56 \\
\hline 21 & 58 & 62 & 64 & 64 \\
\hline 22 & 48 & 48 & 50 & 50 \\
\hline 23 & 52 & 52 & 54 & 54 \\
\hline 24 & 50 & 51 & 52 & 52 \\
\hline 25 & 46 & 56 & 56 & 56 \\
\hline 26 & 62 & 64 & 64 & 64 \\
\hline 27 & 52 & 58 & 60 & 60 \\
\hline 28 & 52 & 52 & 52 & 52 \\
\hline 29 & 58 & 58 & 58 & 58 \\
\hline 30 & 52 & 57 & 58 & 58 \\
\hline 31 & 58 & 62 & 62 & 62 \\
\hline
\end{tabular}

the superior acetabulum. This technique applies tensile forces to the bone-implant interface, thus loosening the implant. There were no complications reported in the origi- 


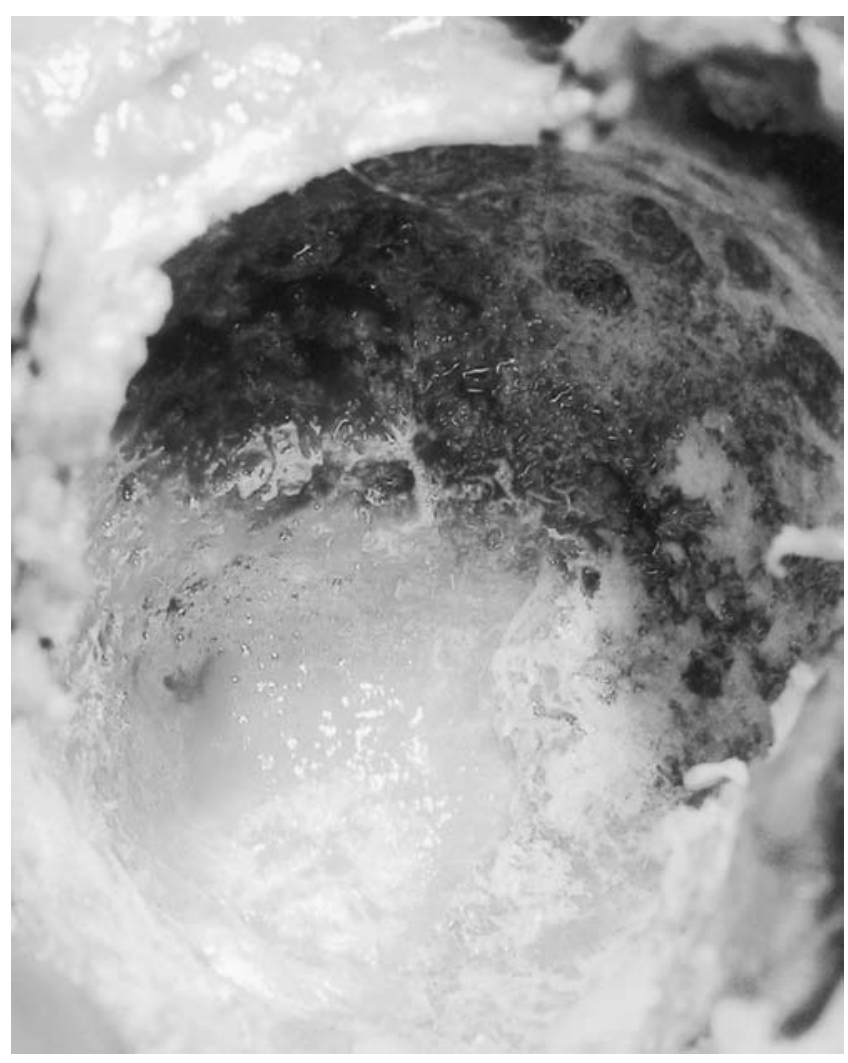

Fig. 5

Typical appearance of host acetabulum after removal of implant.

nal 35 hips described. There is still the need to remove some host bone to implement this technique. Pierson, Jasty and Harris ${ }^{9}$ have described a technique of bending a reciprocating saw blade and using this to loosen the shell without losing medial wall support. They admit that this technique is aggressive and can cause destruction of bone. Markovich, Banks and Hodge ${ }^{10}$ have described a technique, which uses a separate stab incision over a high point on the ilium to introduce a drill into the anterosuperior aspect of the acetabulum and then a punch to drive out the acetabular component. In their original series of 20 patients, acetabular component removal was accomplished within ten minutes. One intra-operative fracture occurred in this series. Another technique involves the sectioning of the acetabular shell with a metal cutting burr, and then removing it piecemeal. This is time consuming, and has the theoretical risk of introducing metal filings into the hip joint with the potential for increased polyethylene wear.

Preservation of bone stock is particularly important in younger patients, such as the group we report here. This concern has led to the development of techniques for exchanging the liner and grafting osteolytic lesions. ${ }^{11}$ In some hips where the implant is non-modular, has a poor track-record, or has been malpositioned, revision of the entire implant is required. The complexity of the acetabular reconstruction is directly proportional to the extent of the resultant acetabular defect. ${ }^{4}$ With increasing frequency, the option of choice in acetabular reconstruction is cementless fixation. ${ }^{12}$ Our treatment of choice for infected total hip replacement is two-stage revision, the success of which depends on the amount of contact with host bone. If there is substantial damage to the host bone, when the component is removed even more bone may have to be reamed away to obtain satisfactory contact. In several hips, after removal of well-fixed components, the resultant cavity was similar to that at a primary arthroplasty (Fig. 5). Previously, we have found removal of well-fixed, cementless, acetabular components to be time consuming, but even in our first 11 hips, the process of removal did not take longer than five minutes.

The existence of so many different techniques reported in the literature probably reflects the fact that the ideal method for removing well-fixed, cementless, acetabular components has yet to be identified. The technique we report in this paper is quick, technically straightforward, successful and free of complications, even in patients where the acetabular component was at Kohler's line. The ease of removal with this system and the lack of any further damage to the host bone illustrate that the Explant Acetabular Cup Removal System is a safe and reliable tool for use in the revision of well-fixed components.

Dr P. A. Mitchell was supported by a grant from the Sir John Charnley Trust.

Although none of the authors have received or will receive benefits for personal or professional use from a commercial party related directly or indirectly to the subject of this article, benefits have been or will be received but are to be directed solely to a research fund, foundation, educational institution, or other non-profit institution, with which one or more of the authors is associated.

\section{References}

1. Mallory TH, Lombardi AV, Fada RA, et al. Noncemented acetabular component removal in the presence of osteolysis: the affirmative. Clin Orthop 2000;381:120-8.

2. Ranawat CS, Peters LE, Umlas ME, Dorr LD. Optimal fixation for acetabular components: the case for cement versus cementless bone ingrown modular sockets. J Arthroplasty 1996;11:1-6.

3. Letournel E. Non-cemented hip implants: failures of biologically fixed devices: causes and treatment. Hip 1987;318-50.

4. D'Antonio JA, Capello WN, Borden LS, et al. Classification and management of acetabular abnormalities in total hip arthroplasty. Clin Orthop 1989;243:126-37.

5. Udomkiat P, Wan Z, Dorr LD. Comparison of preoperative radiographs and intraoperative findings of fixation of hemispheric porouscoated sockets. J Bone Joint Surg [Am] 2001;83-A:1865-70.

6. Lachiewicz PF, Anspach WE 3rd. Removal of a well fixed acetabular component: a brief technical note of a new method. J Bone Joint Surg [Am] 1991;73-A:1355-6.

7. Anspach WE III, Lachiewicz PF. A new technique for removal of the total hip arthroplasty acetabular component. Clin Orthop 1991;268: 152-6.

8. Daum WJ, Calhoun JH. Removal of the acetabular component minimizing destruction of the bone bed. J Arthroplasty 1988;3:379-80.

9. Pierson JL, Jasty M, Harris WH. Techniques of extraction of wellfixed cemented and cementless implants in revision total hip arthroplasty. Orthop Rev 1993;22:904-16.

10. Markovich GD, Banks SA, Hodge WA. A new technique for removing noncemented acetabular components in revision total hip arthroplasty. Am J Orthop 1999;28:35-7.

11. Maloney WJ. Socket retention: staying in place. Orthopaedics 2000; 23:965-6.

12. Dorr LD, Wan Z . Ten years of experience with porous acetabular components for revision surgery. Clin Orthop 1995;319:191-200. 